\title{
Identification of the Molecular Composition of the 205 Proteasome of Mouse Intestine by High-Resolution Mass Spectrometric Proteome Analysis
}

\author{
Reinhold Weber, Regina Preywisch, Nikolay Youhnovski, \\ Marcus Groettrup, and Michael Przybylski
}

\begin{abstract}
Summary
In the last years, intracellular protein degradation by the proteasome has become a focus area of scientific interest. Here, we describe a proteomics approach for the molecular mapping of the constituents of the proteolytically active core particle, the constitutive $20 S$ proteasome from mouse intestine. In addition to the proteomics workflow widely used for protein isolation, gel electrophoretic separation, in-gel digestion, and UV-MALDI mass spectrometry, high-resolution Fourier transform ion cyclotron resonance mass spectrometry using infrared-MALDI ionisation (IR-MALDI FTICR-MS) has been employed as an efficient method for protein identification by peptide mass fingerprint. The $20 \mathrm{~S}$ proteasome subunits $\alpha 1-\alpha 7$ and $\beta 1-\beta 7$ were completely and unambiguously identified. In addition to subunits $\beta 1$ and $\beta 2$, the corresponding inducible subunits being part of the immuno-proteasome were identified. The subunit $\beta 5 \mathrm{i}$ was found to completely replace the corresponding constitutive subunit, suggesting a high proteolytic activity of the intestinal proteasome leading to increased production of antigenic peptides. The high mass accuracy in the low ppm range and resolution of FTICR-MS provide direct identifications of individual proteins as mixtures such as components resulting from incomplete electrophoretic separation. In addition, the comparison of UV-and IR-MALDI FTICR-MS may provide details of fragmentation and rearrangement reactions that may occur under UV-MALDI ionisation conditions.
\end{abstract}

Key words: 20S-Proteasome, High-resolution FTICR mass spectrometry, Proteome analysis, Proteasome constituents, UV- and IR-MALDI ionisation

\section{Introduction}

Protein degradation is essential for cellular viability and the recovery of amino acids for protein biosynthesis. Misfolded proteins and proteins with altered amino acid sequences have to be 
degraded, and protein degradation exerts a key regulatory function in many cellular processes. Degradation can take place in two fundamentally different ways: (1) In the ATP-independent, lysosomal pathway, proteins are internalised into the lysosome and degraded in a relatively unspecific manner and (2) the ATPdependant ubiquitin-proteasome pathway localised in the cytosol and the nucleus $(1-4)$. The importance of the latter process has been recognised by the 2004 Nobel Prizes in Chemistry awarded to Ciechanover, Hershko, and Rose. In proteasomal degradation, ubiquitin, a protein of 76 amino acids highly conserved in all cukaryotic cells, is activated by El (ubiquitin-activating enzyme) followed by conjugation to the protein substrate to be degraded by action of ubiquitin-conjugating enzyme (E2) and ubiquitin-protein ligase (E3). The labelled protein is recognised via the poly-ubiquitin tag and degraded by the $26 \mathrm{~S}$ proteasome, a $2.5 \mathrm{MDa}$ protease complex present in the cytoplasm and nucleus, generating peptide ligands for MHC class I molecules. The $26 \mathrm{~S}$ proteasome consists of two distinct parts, a barrel-shaped proteolytic core complex (20S proteasome) that is capped at both ends by regulatory subunits ( $19 \mathrm{~S}$ proteasome). The $19 \mathrm{~S}$ proteasome recognises ubiquitin-conjugated target proteins and is involved in their unfolding and translocation to the proteolytic core, where proteins are degraded to small (4-15 amino acids) peptides.

The eukaryotic $20 \mathrm{~S}$ proteasome is composed of two copies, each comprising seven different $\alpha$-subunits and seven $\beta$-subunits (1). The $\alpha$ - and $\beta$-subunits each form a heterooligomeric ring with the rings stacked on each other leading to the general assembly $(\alpha 1-\alpha 7)(\beta 1-\beta 7)(\beta 1-\beta 7)(\alpha 1-\alpha 7)$. The subunits can be separated by gel electrophoresis, and 2-D gel electrophoresis has been shown to be an efficient method for component separation $(5,6)$. Since basic proteins tend to migrate out of the gel in immobilised $\mathrm{pH}$-gradients during isoelectric focussing, nonequilibrium $\mathrm{pH}$-gradient gel electrophoresis (NEPHGE) has been used to separate proteasome subunits in the first dimension. After SDS-PAGE and staining, the gel spots are "in-gel" digested and the peptide fragment mixtures subjected to mass spectrometric proteome analysis. Both electrospray ionisation (ESI) and MALDI-MS have been employed as efficient "soft" ionisation-MS methods (7-9). Recently, high-resolution FTICR mass spectrometry (FTICR-MS) has been introduced as a powerful tool in proteome analysis. Because of its unrivalled mass resolving power $\left(>10^{6}\right)$ and accuracy of mass determination (low- to sub-ppm range), FTICR-MS enables unambiguous protein identifications ( 1 ) with only a minimum number of peptide fragments required and (2) with a high efficiency to detect possible structure modifications $(5,6)$. Furthermore, the high mass 
determination accuracy of FTICR-MS allows the application of low mass tolerance thresholds, thus substantially improving the selectivity of database search procedures and the quality of the search results. In addition, specific fragmentation experiments can be carried out in FTICR-MS to ascertain protein identifications, particularly using infrared multiphoton-dissociation (IRMPD) of isolated ions (10-12).

In this study, the proteome analysis of the $20 \mathrm{~S}$ proteasome from mouse intestine is described using both UV- and IRMALDI FTICR-MS. IR laser ionisation (using an Er-YAG laser at $2.94 \mu \mathrm{m}$ emission) has been recently introduced in MALDIMS and employed, in addition to the standard nitrogen UV(337 nm) laser (13-19). Owing to lower irradiation energy, IR-MALDI may provide "softer" ionisation conditions when compared with UV-MALDI, which may be advantageous in the proteome analysis of large biomolecules and the identification of labile, post-translationally modified peptides. Since in MALDIFTICR-MS, relatively long lifetimes of ions between ionisation and detection are required and molecular ions excited by highenergy laser pulses may undergo metastable fragmentation, IRMALDI-MS may provide advantages because of the lower energy for ionisation.

\section{Materials}

\subsection{Isolation of $20 \mathrm{~S}$ Proteasomes from Mouse Intestine}

20S Proteasome from $\mathrm{BALB} / \mathrm{c}$ mouse intestine was isolated as previously described (20).

1. Intestines were cut and grinded in $100 \mathrm{mM} \mathrm{KCl}+0.1 \%$ Triton $\mathrm{X}-100$ in a dounce homogeniser.

2. The tissues were further homogenised under cooling with ice using a Polytron homogeniser.

3. Following ultracentrifugation, proteins were batch purified by DEAE-Sephacel chromatography and precipitated with $\left(\mathrm{NH}_{4}\right)_{2} \mathrm{SO}_{4}(35-80 \%)$ at $3^{\circ} \mathrm{C}$ on ice.

4. The pellet was redissolved in $100 \mathrm{mM} \mathrm{KCl}$, and the protein components were pre-separated by ultracentrifugation on a sucrose gradient ( $15-40 \%$ sucrose in $100 \mathrm{mM} \mathrm{KCl}$ ).

5. The activity of supernatant fractions was determined using a fluorogenic Leu- or Tyr-substrate test and photometric detection $(20,21)$.

6. Positive fractions were pooled, diluted in a ratio of $1: 9$ with $100 \mathrm{mM} \mathrm{KCl}$, and subjected to FPLC. 


\subsection{2-D Gel \\ Electrophoresis}

7. The 20S Proteasomes were finally isolated by FPLC; following confirmation of purity by mini-gel electrophoresis, the pure proteasomes were precipitated with $50 \%$ TCA on ice. After washing with cthanol and acctonc at $-20^{\circ} \mathrm{C}$, the pellet was dissolved in the sample buffer for NEPHGE.

Aliquots of $60-80 \mu \mathrm{g}$ of solubilised proteasome were separated by two-dimensional NEPHGE/SDS-PAGE as described in ref. 22. After the run gels were stained with Coomassie Brilliant blue G 250 using either normal or colloidal staining (23).

Figure 1 illustrates the electrophoretic separation and summarises the identifications for the $20 \mathrm{~S}$ proteasome (Table 1 ). The subunits $\beta 1_{i}, \beta 2_{i}(M E C L-1)$, and $\beta 5_{i}$, which are inducible subunits and therefore part of immuno-proteasomes, were clearly identified. Upon infection, cytokines such as interferon $\gamma$ (IFN- $\gamma$ ) and tumour necrosis factor- $\alpha$ (TNF $\alpha$ ) are released, leading to changes in the architecture of the proteasome: The subunits $\beta 1$ $(\delta), \beta 2(\mathrm{Z})$, and $\beta 5(\mathrm{MB}-1)$ bearing the catalytically active sites of the constitutive proteasome are replaced by the subunits $\beta 1_{i}$ (LMP2), $\beta 2_{i}$ (MECL-1), and $\beta 5_{i}$ (LMP7). These subunits provide catalytic activity, but different cleavage specificity. For example, the exchange of $\beta 1$ to $\beta l_{i}$ was shown to modify the preferred cleavage site from $\mathrm{C}$-terminal peptide bonds of glutamic acid residues to $\mathrm{C}$-terminal bonds of hydrophobic amino acid residues (24). This change leads to an increased number of viral peptides to be presented to $\mathrm{MHC}$ class $\mathrm{I}$, as a larger number of peptides with a suitable $\mathrm{C}$-terminal anchor amino acid become available. In this example, the subunits $\beta 1$ and $\beta l_{i}$ are both present; however, constitutive subunits appear to be stronger expressed than the induced subunits, as indicated by the $2 \mathrm{D}$ gel pattern. The subunits $\beta 2$ and $\beta 2 \mathrm{i}$ are also identified, while the subunit $\beta 5_{i}$ was found to completely replace subunit $\beta 5$. These results

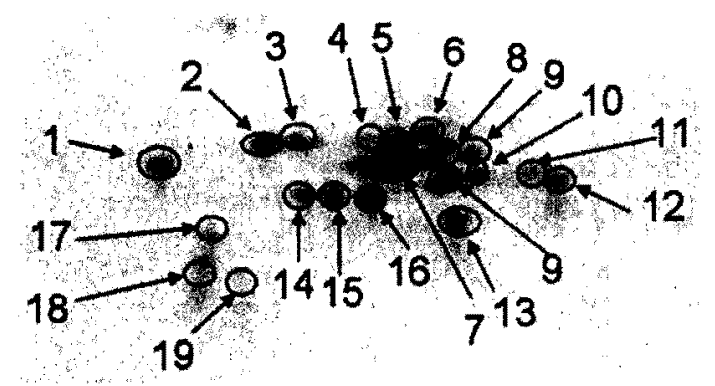

Fig. 1. 2-D gel electrophoresis separation of subunits of the $20 \mathrm{~S}$ proteasome from mouse intestine. Identified subunits are indicated and numbered as listed in Table 1. The systematic nomenclature according to Groll et al. (27) is used. 


\section{Table 1}

Identified subunits from 2-D gel electrophoretic separation of the constitutive 205 proteasome from mouse intestine. The systematic nomenclature according to Groll et al. (27) is used

Spot No. Proteasome subunit m.w. (kDa) SwissProt Accession No.

\begin{tabular}{|c|c|c|c|}
\hline 1 & $\alpha 5$ & 26.4 & Q9Z2U1 \\
\hline 2 & $\alpha 7$ & 28.3 & 070435 \\
\hline \multirow[t]{2}{*}{3} & $\alpha 1+$ & 27.3 & Q9QUM9+ \\
\hline & $\alpha 4$ & 27.8 & Q9Z2U0 \\
\hline 4 & $\alpha 4$ & 27.8 & Q9Z2U0 \\
\hline 5 & $\alpha 6$ & 29.5 & Q9R1P4 \\
\hline 6 & $\alpha .1$ & 27.3 & Q9QUM9 \\
\hline \multirow[t]{2}{*}{7} & $\alpha 3+$ & 29.5 & Q9RIP0+ \\
\hline & $\alpha 1$ & 27.3 & Q9QUM9 \\
\hline 8 & $\alpha 2$ & 25.8 & P49722 \\
\hline 9 & $\beta 2 \mathrm{i}$ & 29.1 & O35955 \\
\hline \multirow[t]{2}{*}{10} & $\beta 6+$ & 26.4 & $009061+$ \\
\hline & $\beta 2 \mathrm{i}$ & 29.1 & O35955 \\
\hline 11 & $\beta 6$ & 29.1 & 009061 \\
\hline 12 & $\beta 2$ & 29.9 & P70195 \\
\hline \multirow[t]{2}{*}{13} & $\beta 5 i_{+}$ & 30.3 & $\mathrm{P} 28063+$ \\
\hline & $\beta 4$ & 22.9 & Q9R1P3 \\
\hline 14 & $\beta 7$ & 29.1 & P99026 \\
\hline 15 & $\beta 7$ & 29.1 & P99026 \\
\hline 16 & $\beta 3$ & 23.0 & Q9RIPI \\
\hline 17 & $\beta 1$ & 25.4 & Q60692 \\
\hline 18 & $\beta l i$ & 23.4 & P28076 \\
\hline 19 & $\beta 1 \mathrm{i}$ & 23.4 & P28076 \\
\hline
\end{tabular}

suggest a high immunoproteasome-type of activity of the $20 \mathrm{~S}$ proteasome from intestine of uninfected mice. The functional implications of this increased production of antigenic peptides remain a subject for future investigation. 


\section{Methods}

\subsection{In-Gel Digestion and Peptide Extraction}

Protein spots were cut out with a scalpel and prepared for tryptic in-gel digestion either manually (25), or by an automated procedure using a DigestPro 96 robot (Intavis Bioanalytical Instruments, Köln, Germany) (26).

1. For manual in-gel digestion, gel spots were washed with water, then dehydrated by addition of $200 \mu \mathrm{L}$ acetonitrile/ water $3 / 2$ (all values $v / v$ ), and dried after removal of supernatant in a SpeedVac (Eppendorf, Germany).

2. The gel pieces were rehydrated in $20 \mathrm{mM} \mathrm{NH}_{4} \mathrm{HCO}_{3}$, destained, and dried. This procedure was repeated until the gel pieces were completely destained $(2-3$ cycles, depending on the size of the gel piece and the intensity of staining).

3. The gel pieces were incubated in a solution of $12.5 \mathrm{ng} / \mu \mathrm{L}$ Trypsin (Promega, Mannheim, Germany) in $20 \mathrm{mM} \mathrm{NH}_{4} \mathrm{HCO}_{3}$ at $4^{\circ} \mathrm{C}$ for $45 \mathrm{~min}$.

4. Following replacement of the supernatant by $20 \mathrm{mM}$ $\mathrm{NH}_{4} \mathrm{HCO}_{3}$, in-gel digestion was carried out for $12 \mathrm{~h}$ at $37^{\circ} \mathrm{C}$.

5. The tryptic peptides were eluted from the gel pieces by treatment each for $1-2 \mathrm{~h}$ with acetonitrile $/ 20 \mathrm{mM} \mathrm{NH}_{4} \mathrm{HCO}_{3}$ (1/1) and acetonitrile $/ 5 \% \mathrm{HCOOH}(1 / 1)$.

6. The combined extracts were lyophilised to dryness and taken up in $10 \mu \mathrm{L} 0.1 \%$ aqueous $\mathrm{CF}_{3} \mathrm{COOH}$.

7. Sample desalting was carried out using ZipTip ${ }^{\mathscr{C}}$ microcolumns (Millipore) according to supplier's recommendation.

Mass spectrometric measurements were carried out on an Apex II FT-ICR mass spectrometer (Bruker Daltonik, Bremen, Germany) equipped with an actively shielded $7 \mathrm{~T}$ superconducting magnet and a cylindrical Infinity analyser cell. The pulsed nitrogen laser of the Scout 100 MALDI source is operated at $337 \mathrm{~nm}$. Ions were cooled immediately after desorption by pulsed $\mathrm{Ar}$ gas and accumulated in a hexapole ion guide situated $1 \mathrm{~mm}$ in front of the target. In UV-MALDI, 15-20 laser shots per scan were used. A solution of $100 \mathrm{mg} / \mathrm{mL} 2,5$-dihydroxybenzoic acid in acetonitrile $/ 0.1 \%$ aqueous TFA $(2 / 1)$ was used as matrix. The IRMPD fragmentation experiments were carricd out using a $\mathrm{CO}_{2}$ laser (Synrad, Mukilteo, WA) at a wavelength of $10.6 \mu \mathrm{m}$. Ions of interest were isolated using SWIFT with a correlation sweep according to $100-4,000 \mathrm{~m} / \mathrm{z}$ and an ejection safety belt of $500 \mathrm{~Hz}$. After cooling with pulsed Ar gas for $80-120 \mathrm{~ms}$, the parent ions were fragmented by IR-irradiation for 0.4-0.75 $\mathrm{s}$. 
All components of the 20S proteasome of mouse intestine separated by 2 -D gel electrophoresis were unambiguously identified by UV-MALDI FTICR-MS following tryptic in-gel digestion. The high mass determination accuracy of the FTICR-MS enabled the setting of low mass tolerance thresholds in the subsequent database search, leading to high scores equivalent with identifications with high probability. Representative examples of spectra and identifications of proteins are shown in Fig. 2.

The high mass accuracy determination and high resolution of the FTICR-MS method can provide the direct identification of individual protein components in mixtures, as illustrated by the example of two proteasome components in Fig. 3. In some cases, the resolution of the gel electrophoresis was found insufficient to separate individual proteasome subunits, which is frequently indicated by a cloudy spot shape. In the example in Fig. 3 (Spot No. 13 in Fig. 1), unequivocal identification of the two proteasome components $\beta 5 i$ and $\beta 4$ was obtained, thus indicating that high mass accuracy of FTICR-MS and minimum number of peptides required for database identification may overcome the problem of insufficient electrophoretic resolution of protein complexes.

The identification of proteins by peptide mass fingerprint can be ascertained by tandem mass spectrometric fragment analysis. As shown in Fig. 4, the proteasome subunit C5 ( $\beta 6$ ) was identified by database search with the monoisotopic masses of the tryptic peptide ions. For confirmation, the peptide with $m / z=1545.75$ was isolated and fragmented by IRMPD as described above. In the IRMPD-spectra, the typical, abundant series of b- and $y$-ions could be observed. In addition, the fragment ions at $m / z 1527.7277$ and 788.4041 can be assigned as condensation products of the parent ion and the y 7 ion, respectively. Similar to the IR-laser ionisation described later, the loss of water is favoured at elevated temperatures. All mass values could be assigned to the corresponding sequences, thus confirming the identifications obtained by peptide mass fingerprint.

3.3. IR-MALDI-FTICR Mass Spectrometry
The Scout 100 MALDI source of the FTICR-mass spectrometer was modified to accommodate an additional Q-switched $2.94 \mu \mathrm{m}$ Er:YAG laser (originally produced by Bioptic, Berlin, Germany), as previously described in ref. 19. The maximum pulse energy of the laser $(7 \mathrm{~mJ})$ was decreased by an attenuator at a repetition rate of $5 \mathrm{~Hz}$ until signals could be obtained. In IR-MALDI, only 5-10 laser shots were used because of strong ablation of the matrix. Although matrices such as succinic acid can be employed for IR-MALDI-MS, a solution of $100 \mathrm{mg} / \mathrm{mL} 2,5$-dihydroxybenzoic acid in acetonitrile $/ 0.1 \%$ aqueous TFA $(2 / 1)$ was found to give best performance for IR-MALDI FTICR-MS. 
a

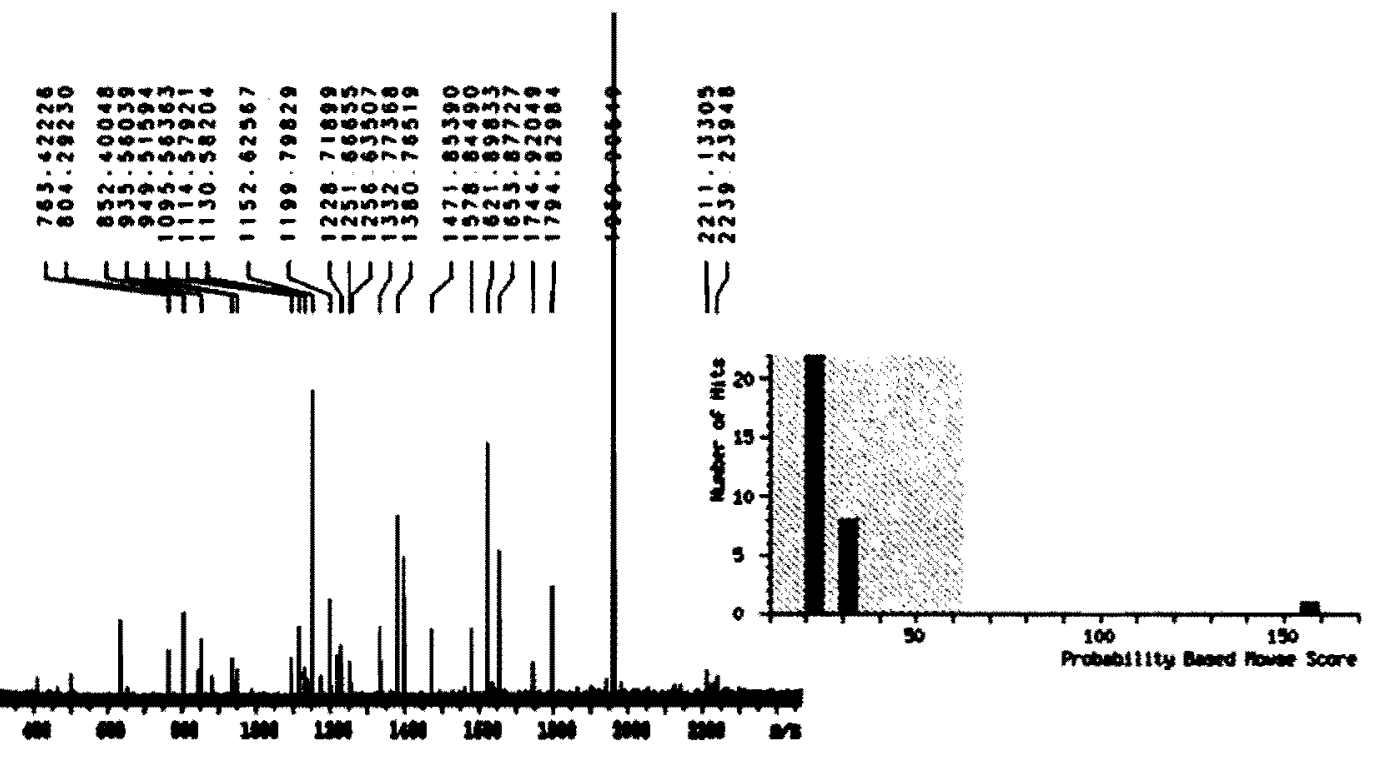

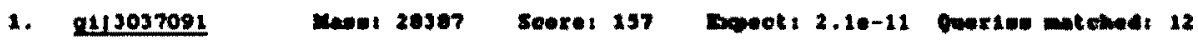
protessome alphap/co subunit (thü mueculua)

b

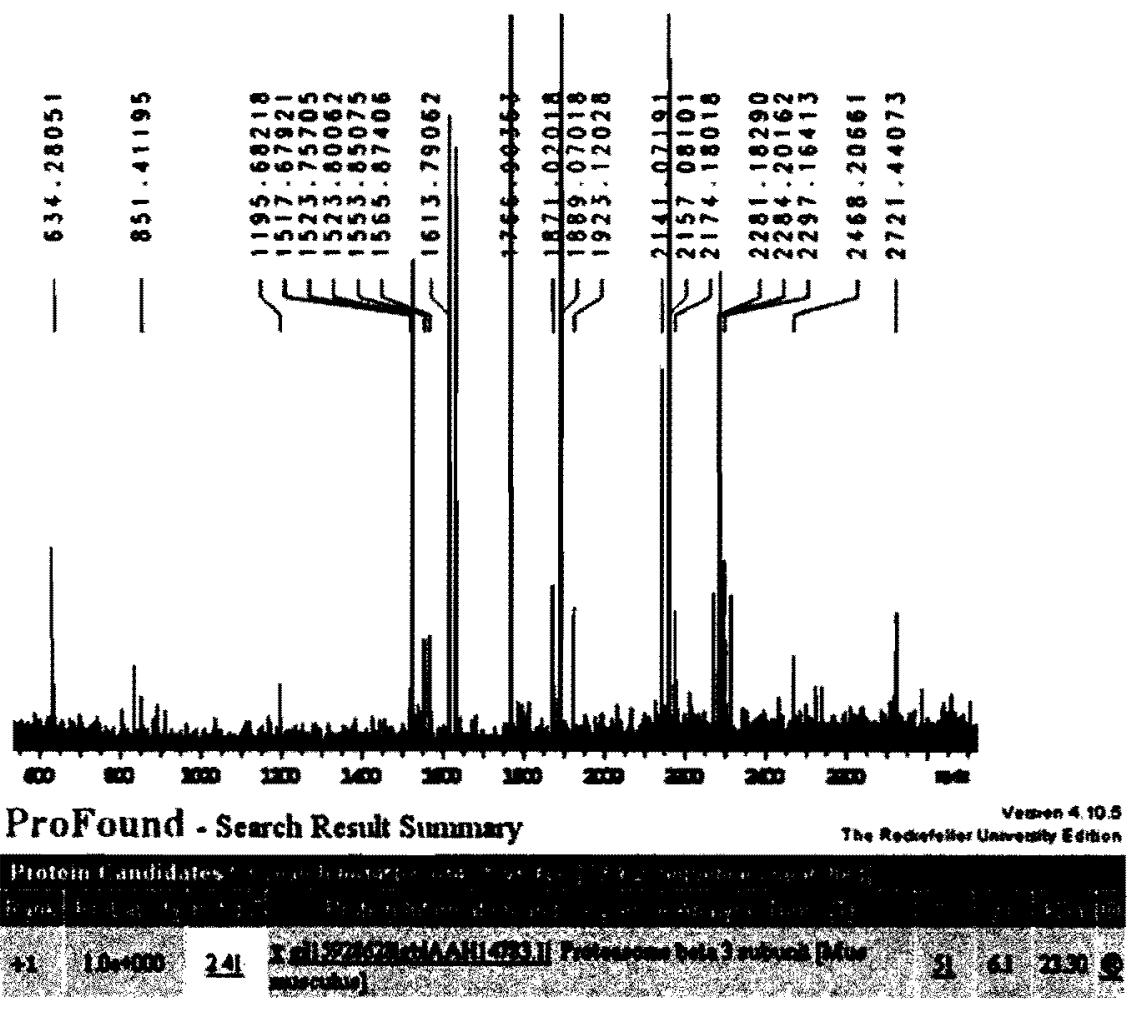

Fig. 2. MALDI FT-ICR-mass spectrum and identification of proteasome subunits $\alpha 7$ (a) and $\beta 3$ (b). 


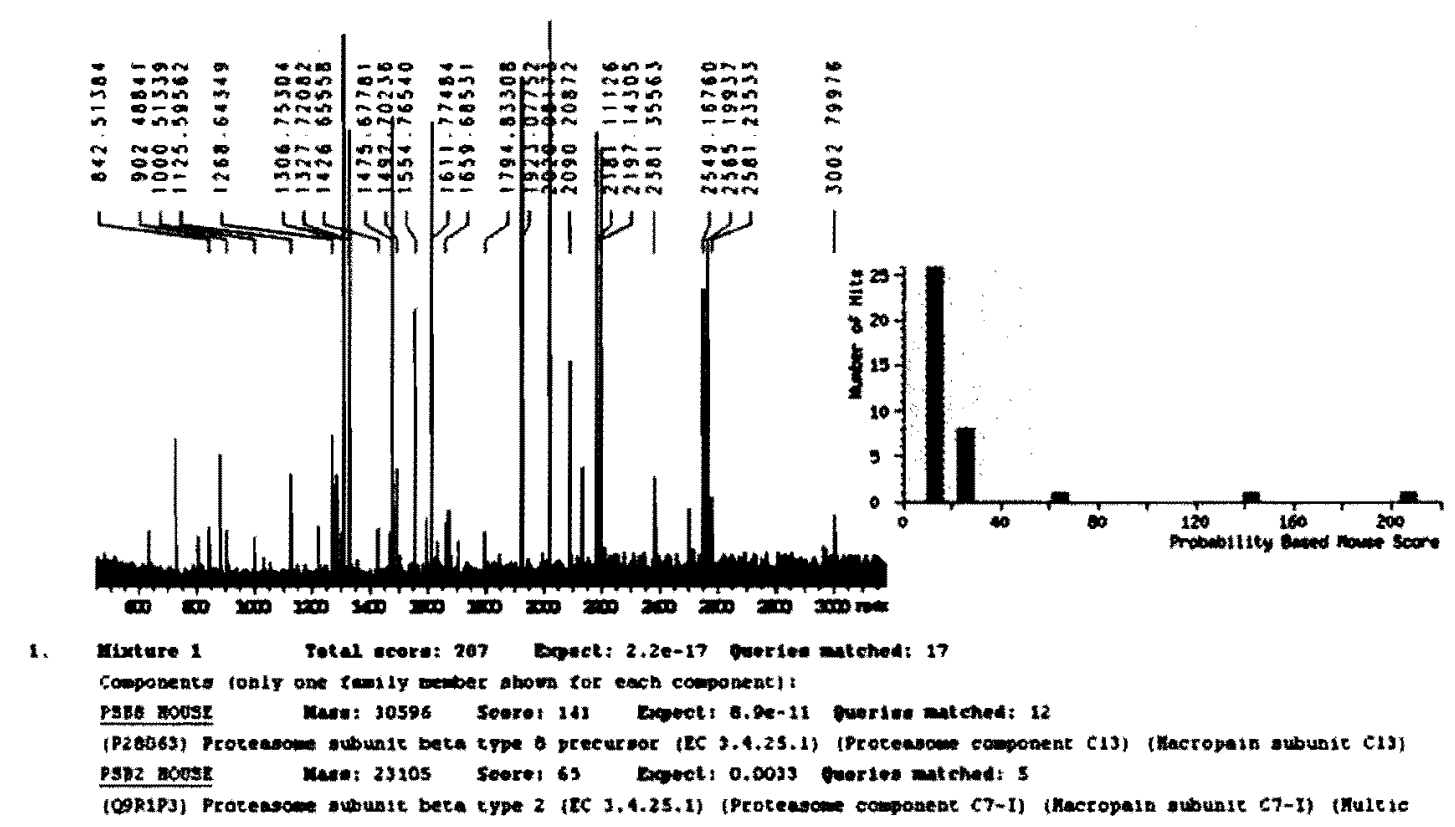

Fig. 3. MALDI FT-ICR mass spectrum and identification of a mixture of two different proteasome subunits.

The subunits $\alpha 1, \alpha 6, \beta 1$, and $\beta 6$ were unambiguously identified with high mass accuracies by peptide mass fingerprinting. Although UV- and IR-MALDI spectra generally showed a similar pattern, some characteristic differences were noted (see Table 3). A comparison of sequence coverages obtained in protein identifications by UV- and IR-MALDI FTICR-MS on tryptic in-gel digestion is given in Table 2; in both UV- an IR-MALDI, sequence coverages ranged from $15 \%$ to approximately $55 \%$.

The comparative search for isobaric peptides in UV- and IRMALDI FTICR-MS revealed more detailed information about fragmentation reactions, leading to modified peptides, which have been found to occur even under "soft ionisation" MALDI conditions. Generally, enhanced thermal fragmentation reactions were observed by IR-MALDI owing to elevated temperature in IR-irradiation. In contrast, photochemical fragmentation reactions are found enhanced by UV-MALDI, which are absent in IR-MALDI. The comparison of UV- and IR-MALDI FTICR spectra of tryptic peptides from subunit $\beta 1$ reveals details of fragmentation and rearrangement reactions (Fig. 5, Table $\mathbf{3}$ ). For example, the higher abundance of the peptide (pyroE156 $\mathrm{R} 177$ ) in comparison with the unmodified (Q156 - R177) in the IR-MALDI spectrum can be explained by the preferential release of ammonia at elevated IR-MALDI temperature conditions. In contrast, the peptide ion, $m / z 2265,28$ was identified 

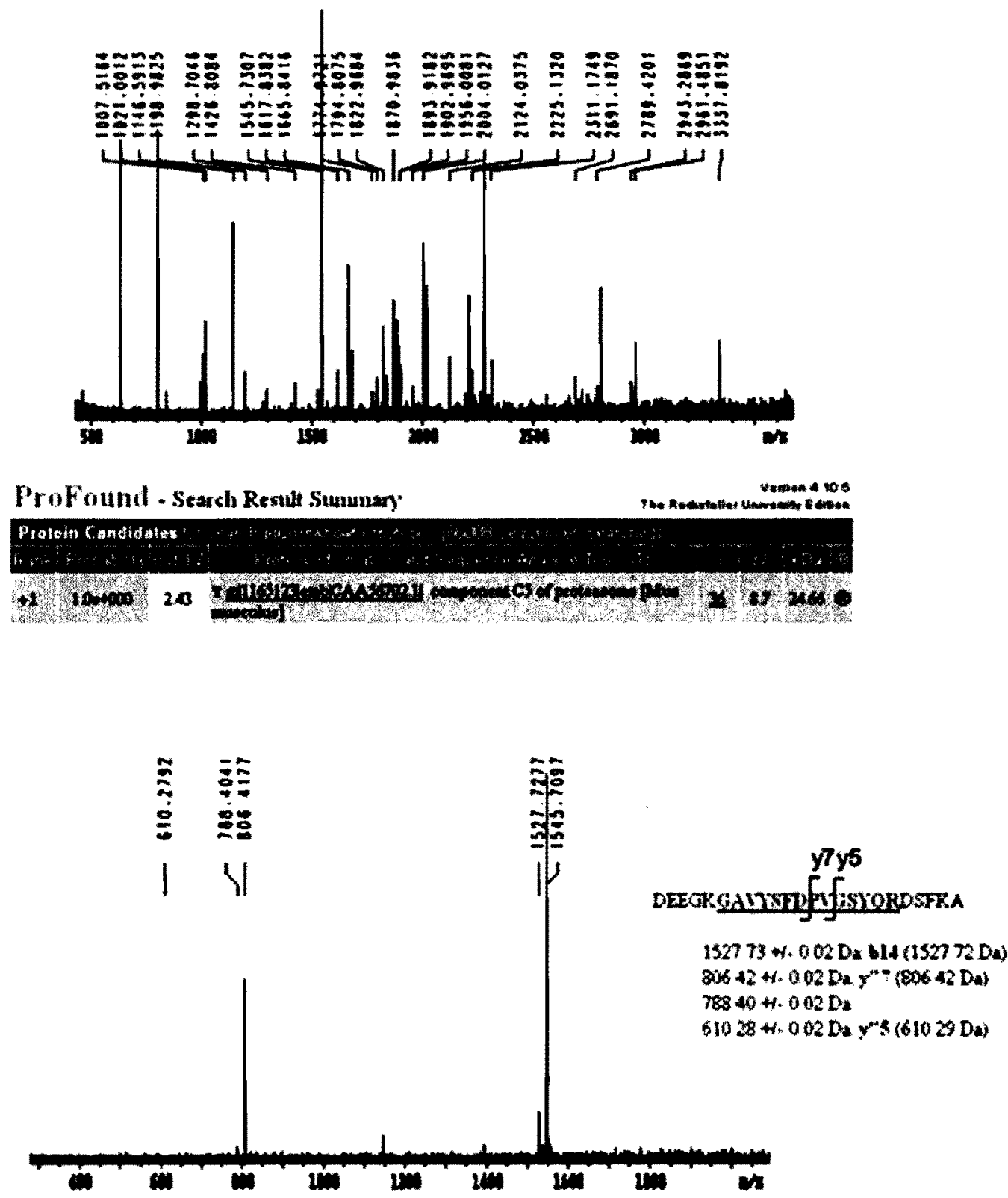

gil11651231emblCAA56702.11 component C5 of proteasome [Mus musculus] mass $=249476$ Da, pI $=8.7$

Fig. 4. MALDI FT-ICR mass spectrum and identification of proteasome subunit C5 ( 36 ) (a) and IRMPD of the parent ion $m / z 1545.73$ (b). The spectrum is dominated by sequence-specific $b$ - and $y$-ions. Owing to the high accuracy of mass determination, direct peptide sequence assignment of the mass values is possible. Using this complementary technique, the results from peptide mass fingerprints could be confirmed.

as a photochemical deamidation product of the peptide fragent, (209-229) (LAAIQESGVERQVLLGDQIPK) in the UV-MALDI spectrum. This peptide and corresponding peptides were found unmodified in IR-MALDI-MS. 


\section{Table 2}

Comparison of percent sequence coverage values of proteasome subunits identified by UV-MALDI and IR-MALDI-MS

\begin{tabular}{lll} 
Proteasome subunit & $\begin{array}{l}\text { Sequence coverage } \\
\text { UV-MALDI (\%) }\end{array}$ & $\begin{array}{l}\text { Sequence coverage } \\
\text { IR-MALDI (\%) }\end{array}$ \\
\hline$\alpha 1$ & 40 & 18 \\
$\alpha 6$ & 28 & 20 \\
$\beta 1$ & 15 & 32 \\
$\beta 6$ & 56 & 40 \\
\hline
\end{tabular}

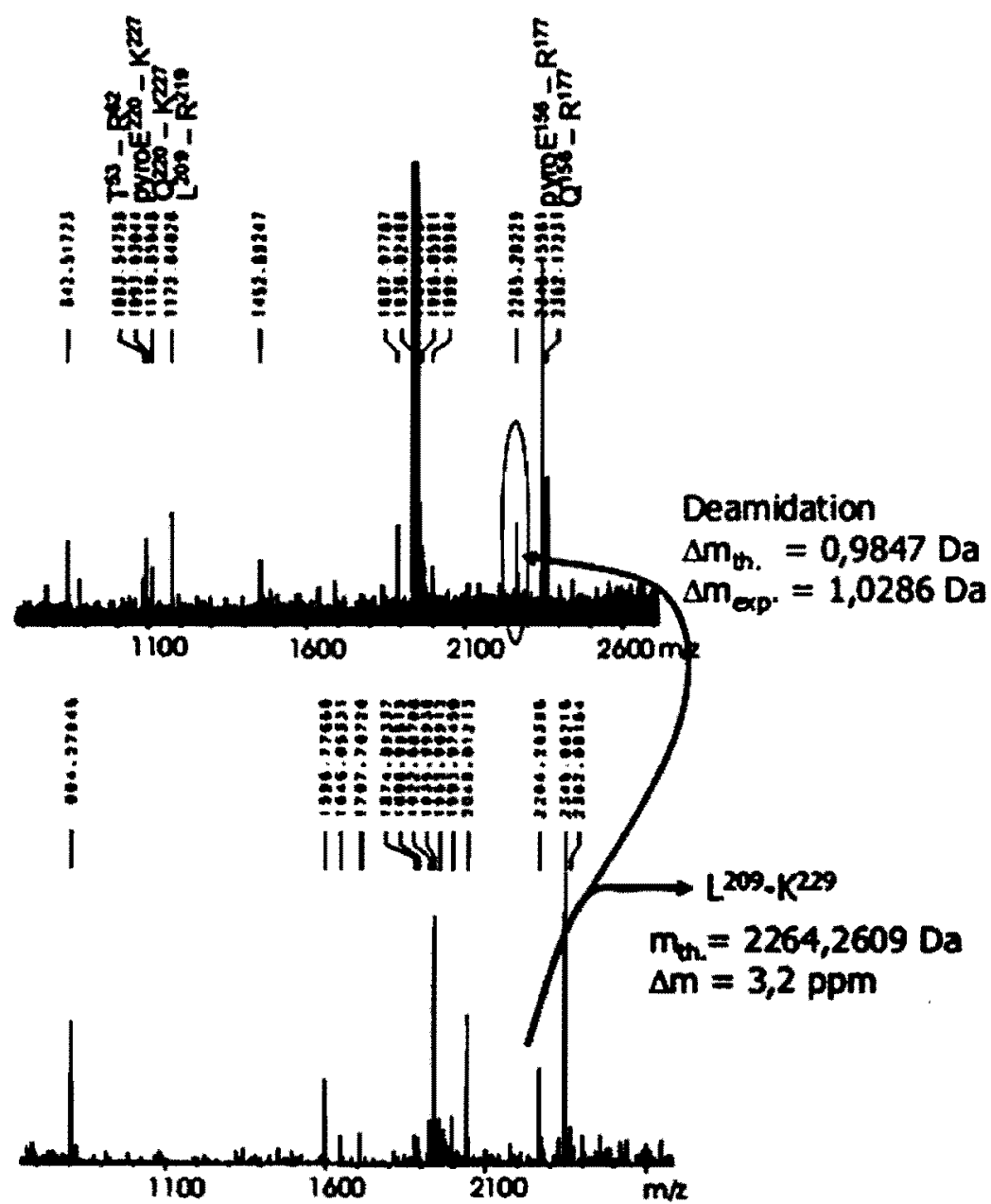

Fig. 5. Comparison of (a) UV- and (b) IR-MALDI FT-ICR mass spectra of subunit $\alpha 1$ reveals details of fragmentation and rearrangement reactions (see text and Table 3 ). The ion signal at $m / z=2265,28$ in the UV-MALDI-spectrum is a photochemical deamidation product of the peptide L ${ }^{209}$ AAIQESGVERQVLLGDQIPK ${ }^{229}$. 


\section{Table 3}

Comparison of identified peptides from proteasome subunit $\beta 1$ using UV- and IRMALDI FT-ICR mass spectrometry. The peak with the mass 2264.2376 amu in the UV-MALDI spectrum is the result of a photochemical deamidation product of the peptide L ${ }^{209}$ AAIQESGVERQVLLGDQIPK ${ }^{29}$, which can be observed intact in IR-MALDI. In the higher mass range, IR-MALDI provides better mass accuracies than UVMALDI

Sequence $\quad m_{\text {th }}$ (amu) $m_{\text {exp }}$ (amu) (UV) $\Delta m$ (ppm) $m_{\text {exp }}$ (amu) (IR) $\Delta m$ (ppm) Modification

\begin{tabular}{lllllll}
\hline $\mathrm{T}^{53}-\mathrm{R}^{62}$ & 1082.5356 & 1082.5397 & 3.8 & & & \\
pyroE $^{220}-\mathrm{K}^{227}$ & 1092.6180 & 1092.6225 & 4.1 & & & $\mathrm{Q} \rightarrow$ pyroE \\
$\mathrm{Q}^{220}-\mathrm{K}^{227}$ & 1109.6445 & 1109.6486 & 3.6 & & & \\
$\mathrm{~L}^{209}-\mathrm{R}^{219}$ & 1171.6197 & 1171.6324 & 10.8 & & & \\
$\mathrm{~L}^{209}-\mathrm{K}^{229}$ & 2263.2536 & & & 2263.2458 & 3.5 & \\
$\mathrm{~L}^{209}-\mathrm{K}^{229}$ & 2264.2376 & 2264.2458 & 7.4 & & & $\mathrm{Q}$ deamidated \\
pyroE & & & & & \\
$\mathrm{Q}^{156}-\mathrm{R}^{177}$ & 2344.0648 & 2344.1177 & 22.5 & 2344.0543 & 4.4 & $\mathrm{Q} \rightarrow$ pyroE \\
\hline
\end{tabular}

3.4. Database Search Procedures
The monoisotopic masses of singly charged ions were directly used for database search using the following publicly available programmes: Mascot (http:/ $/$ www.matrixscience.com $/ \mathrm{cgi} / \mathrm{search}$ form.pl?FORMVER = 2\&SEARCH = PMF), MS-Fit (http: $/$ prospector.ucsf.edu/ucsfhtml $4.0 / \mathrm{msfit} . \mathrm{htm}$ ), and ProFound (http://prowl.rockefeller.edu/profound_bin/WebProFound. exe). Both SwissProt and NCBInr were employed as databases. For MS/MS, PepFrag (http://prowl.rockefeller.edu/prowl/ pepfragch.html) was used for database search.

\section{Notes}

In IR-MALDI-MS, the laser power and number of laser shots must be carefully adjusted. Best results were obtained in cases when matrix ablation occurs at a visible rate. A too high laser power or focus will lead to a drastic decrease of the number of ions produced. In UV-MALDI-MS, attention should be given to the possible formation of photochemical reactions such as deamidation, and laser energies should be adjusted accordingly. 


\section{Acknowledgements}

This work was supported by grants from the Deutsche Forschungsgemeinschaft (DFG), Bonn (1517/4-2 to M.G., M.P.; $175 / 10-2$ to M.P).

\section{References}

1. Voges, D., Zwickl, P., and Baumeister, W. (1999) The $26 \mathrm{~S}$ proteasome: A molecular machine designed for controlled proteolysis. Annu Rev Biochem 68: 1015-68.

2. Hershko, A. and Ciechanover, A. (1992) The ubiquitin system for protein degradation. Annu Rep Biochem 61: 761-807.

3. Ciechanover, A., Orian, A., and Schwartz, A.L. (2000) The ubiquitin-mediated proteolytic pathway: Mode of action and clinical implications. J Cell Biochem 77(\$34): 40-51.

4. Ciechanover, A. (2005) Proteolysis: From the lysosome to ubiquitin and the proteasome. Nat Rev Mol Cell Biol 6(1): 79-87.

5. Damoc, E., Youhnovski, N., Crettaz, D., Tissot, J.D., and Przybylski, M. (2003) High resolution proteome analysis of cryoglobulins using Fourier transform-ion cyclotron resonance mass spectrometry. Proteomics 3(8): 1425-33.

6. Bai, Y., Galetskiy, D., Damoc, E., Paschen, C., Iju, Z., Griese, M., Liu, S., and Przybylski, M. (2004) High resolution mass spectrometric alveolar proteomics: Identification of surfactant protein SP-A and SP-D modifications in proteinosis and cystic fibrosis patients. Proteomics 4(8): 2300-9.

7. Smith, R.D., Loo, J.A., Edmonds, C.G., Barinaga, C.J., and Udseth, H.R. (1990) New developments in biochemical mass spectrometry: Electrospray ionization. Anal Chem 62(9): 882-99.

8. Glocker, M.O., Bauer, S.H., Kast, J., Volz, J., and Przybylski, M. (1996) Characterization of specific noncovalent protein complexes by UV matrix-assisted laser desorption ionization mass spectrometry. I Mass Spectrom 31(11): 1221-7.

9. Przybylski, M., and Glocker, M.O. (1996) Electrospray mass spectrometry of biomacromolecules complexes with non-covalent interactions - new analytical perspectives for supramolecular chemistry and molecular recognition processes. Angew Chem Int Ed Engl 35(8): 806-26.

10. van der Rest, G., He, F, Emmett, M.R., Marshall, A.G., and Gaskell, S.J. (2001) Gas-phase cleavage of PTC-derivatized electrosprayed tryptic peptides in an FT-ICR trapped-ion cell: Mass-based protein identification without liquid chromatographic separation. I Am Soc Mass Spectrom 12(3): 288-95.

11. Wigger, M., Eyler, J.R., Benner, S.A., Li, W., and Marshall, A.G. (2002) Fourier transformion cyclotron resonance mass spectrometric resolution, identification, and screening of non-covalent complexes of Hck Src homology 2 domain receptor and ligands from a 324-member peptide combinatorial library. JAm Sac Mass Spectrom 13(10): 1162-9.

12. Laskin, J., and Futrell, J.H. (2005) Activation of large ions in FT-ICR mass spectrometry. Mass Spectrom Rev 24(2): 135-67.

13. Laiko, V.V., Taranenko, N.I., Berkout, V.D., Yakshin, M.A., Prasad, C.R., Lee, H.S., and Doroshenko, V.M. (2002) Desorption/ionization of biomolecules from aqueous solutions at atmospheric pressure using an infrared laser at 3 microm. J Am Soc Mass Spectrom 13(4): 354-61.

14. Feldhaus, D., Menzel, C., Berkenkamp, S., Hillenkamp, F., and Dreisewerd, K. (2000) Influence of the laser fluence in infrared matrixassisted laser desorption/ionization with a 2.94 microm Er: YAG laser and a flat-top beam profile. JMass Spectrom 35(11): 1320-8.

15. Menzel, C., Dreisewerd, K., Berkenkamp, S., Hillenkamp, F. (2001) Mechanisms of energy deposition in infrared matrix-assisted laser desorption/ionisation mass spectrometry. Int $J$ Mass Spectrom 207: 73-96.

16. Berkenkamp, S., Menzel, C., Hillenkamp, F., and Dreisewerd, K. (2002) Measurements of mean initial velocities of analyte and matrix ions in infrared matrix -assisted laser desorption ionization mass spectrometry. J Am Soc Mass Spectrom 13(3): 209-20.

17. Cramer, R, Richter, W.J., Stimson, E., and Burlingame, A.L. (1998) Analysis of phosphoand glycopolypeptides with infrared matrixassisted laser desorption and ionization. Anal Chem 70 (23): 4939-44.

18. Budnik, B.A., Jensen, K.B., Jorgensen, T.J., Haase, A., and Zubarev, R.A. (2000) Benefits of 2.94 micron infrared matrix-assisted laser desorption/ionization for analysis of 
labile molecules by Fouricr transform mass spectrometry. Rapid Commun Mass Spectrom 14(7): 578-84.

19. Petre, B.A., Youhnovski, N., Lukkari, J., Weber, R. and Przybylski, M. (2005) Structural characterisation of tyrosine-nitrated peptides by ultraviolet and infrared matrix-assisted laser desorption/ ionisation Fourier transform ion cyclotron resonance mass spectrometry. Eur J Mass Spectrom (Chichester, Eng) 11(5): 513-8.

20. Schmidtke, G., Emch, S., Groettrup, M., and Holzhutter, H.G. (2000) Evidence for the existence of a non-catalytic modifier site of peptide hydrolysis by the 20 S proteasome. $J$ Biol Chem 275(29): 22056-63.

21. Schwarz, K, van den Broek, M., Kostka, S., Kraft, R., Soza, A., Schmidtke, G., Kloetzel, P.M., and Groettrup, M. (2000) Over expression of the proteasome subunits LMP2, LMP7, and MECL-1, but not PA28 alpha/ beta, enhances the presentation of an immunodominant lymphocytic choriomeningitis virus T cell epitope. J Immunol 165(2): 768-78.

22. Groettrup, M., Kraft, R, Kostka, S., Standera, S., Stohwasser, R., and Kloetzel, P.M. (1996) A third interferon-gamma-induced subunit exchange in the 20 s proteasome. Eur J Immunol 26(4): 863-9.
23. Neuhoff, V., Arold, N., Taube, D., and Ehrhardt, W. (1988) Improved staining of proteins in polyacrylamide gels including isoelectric focusing gels with clear background at nanogram sensitivity using Coomassie Brilliant Blue G-250 and R-250. Electrophoresis 9: 255-62.

24. Groettrup, M., Ruppert, T., Kuehn, L., Seeger, M., Standera, S., Koszinowski, U., and Kloetzel, P.M. (1995) The interferongamma-inducible II S regulator (PA28) and the LMP2/LMP7 subunits govern the peptide production by the $20 \mathrm{~S}$ proteasome in vitro. $J$ Biol Chem 270(40): 23808-15.

25. Mortz, E., Vorm, O., Mann, M., and Roepstorff, P. (1994) Identification of proteins in polyacrylamide gels by mass spectrometric peptide mapping combined with database search. Biol Mass Spectrom 23(5): 249-6l.

26. Houthaeve, T., Gausepohl, H., Ashman, K., Nillson, T., and Mann, M. (1997) Automated protein preparation techniques using a digest robot. J Protein Chem 16(5): 343-8.

27. Groll, M., Ditzel, L., Lowe, J., Stock, D., Bochtler, M., Bartunik, H.D., and Huber, R. (1997) Structure of $20 \mathrm{~S}$ proteasome from yeast at 2.4 A resolution. Nature $386(6624)$ : $463-71$. 